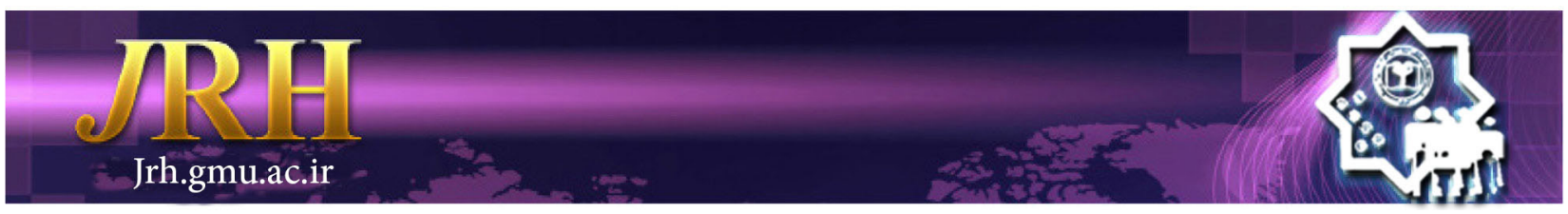

\title{
A comparison among meta-cognition, anxiety and depression components in the mothers of children with mental disorders
}

Narges Zamani ${ }^{1}$

\author{
Journal of Research \& Health \\ Social Development \& Health Promotion \\ Research Center \\ Vol. 9, No. 5, Sep \& Oct 2019 \\ Pages: $373-380$ \\ DOI: $10.29252 / j r h .9 .5 .373$ \\ Original Article
}

1. Correspondence to: Department of Health Psychology, Young Researchers and Elite Club, Hamedan Branch, Islamic Azad University, Hamedan, Iran

Email: Nargeszamani1367@iauh.ac.ir

Received: 22 Dec 2014

Accepted: 28 Jan 2015

How to cite this article: Zamani N. A comparison among meta-cognition, anxiety and depression components in the mothers of children with mental disorders. $J$ Research \& Health2019; 9(5): 373 - 380.

\begin{abstract}
Meta-cognition is one of the high cognitive processes of brain which has positive relationship with other cognitive capacities and is considered as a predisposing factor in lots of psychopathologies. The aim of the present study was to examine the relationship between meta-cognition and anxiety and depression in the mothers of children with mental disorders. It was a study conducted on the mothers of 2 to 14 year-old children. 143 mothers with mental disorders (developmental disorders and disruptive behavior disorders) were selected through purposive sampling. They were assessed using meta-cognitive beliefs questionnaire, Spielberger anxiety questionnaire, and Beck depression inventory-II. Data analysis showed that there was a significant difference in the rate of anxiety, depression and meta-cognition among the mothers of children with mental disorders. Psychological health of these mothers was low so the use of a systemic approach will be useful in solving the problems of such families.
\end{abstract}

Keywords: Anxiety, Depression, Meta-Cognition, Mental Disorders

\section{Introduction}

Many changes emerge with the arrival of a child to the couple relationship influencing their mental health. Parents will tolerate many stresses due to adaption with the changes. Sometimes couples, experience negative changes in terms of stress, self-esteem, communication and conflict, but child birth does not harm the marriage [1]. Although having a child gives a sense of joy, pride, and personal development to mother it brings about challenges which may cause negative effects. So the parents have the high levels of anxiety and depression than those who do not have any children [2]. In addition, the mothers of children with physical and mental disabilities and special needs undergo a lot of pressure and stress [3].

Care for a sick child has a serious impact on families. Many studies show that the parents of children with special need deal with increasingly stress compared with the parents of healthy children [4-6]. However, this effect depends on the nature of the child disorder and family variables. Sudden disorders with acute start, compared with chronic diseases have different effects on family life. In addition a disorder may face the family with different challenges in different periods [7]. For example, during the child growth, his behavior becomes more challenging and new 
issues arises in the field of social communication with his transition into adolescence [8].

Mental disorders not only create ineffective psychiatric diseases, but also affect families severely and impair their performance. Also it has effects on mental health, decreases family welfare and imposes many pressures [9]. When a family member suffers from a mental disorder, all family members involve with a disease and its consequences. In addition, great pressures will be imposed on them [10]. The parents of children with mental disorder, not only face with the issue of patient care, but also they should care of patient's siblings who are impaired to a greater extent of subliminal disorders than others [3]. Lainhart [11] examined the incidence of mental health problems in parents and siblings of children with mental disorders. He argued that the families are at a high risk of problems for mental health due to their stress and pressure of caring. When a child has a mental disorder in the family, his brothers and sisters will get in trouble and will probably face with problems [7] like higher levels of anxiety and the feelings of rejection or trying to compensate the behaviors of their brothers and sisters [12]. Many parents cannot delegate the care of their children with mental disorder to others so they do not devote time to themselves and consequently some problems emerges to the parents' relationship and their marital satisfaction will be decreased [13]. The consequence associated with mental disorders is an important component of the imposed pressure on families having children with mental disorders [7]. Labeling is not limited to people close to the patient. In fact, it spreads over generations and transfers to larger sections of the family [8]. Labeling is a psychological trauma which is often neglected and amplifies guilty feeling in the families of patients with mental disorders.

Mood disorders are a group of clinical disorders characterized by losing the sense of mastery in which the person suffers enormously [14]. The World Health Organization estimated that depression and stress disorders were at the top of the mental health list including the reason of about 25 percent of referrals to the health centers in the world [15]. Having children in troubled cause mood disorders such as anxiety and depression in parents, especially mothers [3].

Meta-cognition refers to one's awareness of thought processes and his ability to manage cognitive processes [16]. The central idea of meta-cognitive therapy comes from the crucial role of the cognitive factors in psychological disorders which create inutility intellectual styles leading to the persistence of negative emotions [17]. Meta-cognition is an important factor in the development and the persistence of psychiatric disorders [18].

Meta-cognition indexes direct attention, determine thinking style and lead to recall the coping responses, which frequently result in producing inadequate information. Thus, based on this view, the origin of the diversity in these beliefs and thoughts is static meta-cognition. According to this viewpoint, instead of repairing the products of metacognition index, irrational beliefs, negative automatic beliefs, and primary maladaptive schemas, we should target the meta-cognition indexes themselves [19].

According to the meta-cognitive approach, the patient is able to establish a new relationship with his thoughts, beliefs and behavior, rather than as a traditional cognitive behavioral approach in which the credibility of his thoughts and beliefs is challenged. The therapist in this approach must change metacognition indexes that trigger uncontrollable and maladaptive negative recurrent thinking styles [20]. Prior researches revealed that thoughts have important influence on emotional and psychological well-being. The main assumption is that psychological disorder is the result of expanding some thoughts and throwing away other thoughts. The main cause of this situation is the selection process and the styles of thought control which are related to meta-cognition. In addition, this is a way to communicate with our inner experiences [21]. Meta-cognition indexes emphasize on internal cognitive factors that control, 
monitor and evaluate our thoughts. Metacognition is divided into three main categories: meta-cognitive knowledge, meta-cognitive experiences and meta-cognitive strategies [22]. Based on Meta-cognition approach, the treatment should include eliminating anxiety, releasing threatening strategies and helping individuals to experience troublesome thoughts without avoiding or reacting to them through impractical suppression strategies or strategies based on exaggeration of thoughts or worry [23]. Meta-cognition indexes, irrational beliefs and negative automatic thoughts in mothers with special needs are higher than other mothers due to their guilty and inefficient feelings [24-25].

Given the above, mental health for families, especially mothers of sick children in the course of treatment and the prognosis of the disorder is crucial so the first goal of this study was to compare the components of meta-cognition, anxiety and depression in the mothers of children with mental disorders [26]. On the other hand, considering the role of meta-cognition in producing and continuity of anxiety and depression disorders [27], was another goal of this study. We examined the amount of meta-cognition thought in the mothers of children with mental disorders and evaluated its relationship with their anxiety and depression. Assessing these parameters can be helpful in planning the health and education of parents having children with special needs and exceptionally.

\section{Method}

The statistical population of this cross-sectional study contained the mothers of children ( 2 to 14 year-old) with mental disorders who lived in Hamedan west of Iran between the spring and summer in 2014. The study sample consisted of 143 mothers of children with mental disorders (developmental disorders and disruptive disorders) who referred to rehabilitation centers and centers and clinics under the supervision of welfare organization. We applied selected purposive sampling. A neurologist of children and adolescents diagnosed the children with physical and mental disorders. Inclusion criteria were as follows: at least passing the guidance school; age range from 19 to 42 years old, and not having comorbid disorders of anxiety and depression in the Diagnostic Disorders of DSM-5.

Spielberger state trait anxiety questionnaire: The State Trait Anxiety Inventory form (STAI-X) was introduced in 1970 by Spielberger et al. It aims to measure the anxiety intensity from low to high. For this scale, low scores represent tranquility, average scores represent the average levels of stress and anxiety, and high scores reflect intense fear close to panic and phobia. Respondents indicated the intensity of their feelings on a four scale about how they generally feel [24]. This scale was revised in 1983 with the aim of preparing the net amount of anxiety to provide a solid basis for differentiating the diagnosis of patients with anxiety disorders from those with depression. In the revised form of the STAI-Y, twelve items out of forty ( $30 \%$ items of form $\mathrm{X})$ has been changed [25]. It is a valid instrument with good reliability. The correlation of this instrument with Kattel anxiety questionnaire also showed its validity and reliability which has been demonstrated in several studies. Spielberger et al. [26] reported the correlation of its Spanish and Hindi version with its English form between 0.83 and 0.94 respectively.

Chadori reported that the correlation of Bengali and English form between women and men were 0.92 and 0.89 in state anxiety and 0.91 and 0.94 in trait anxiety respectively. In the Mahram study cronbach's alpha was used to calculate the validity in the anxiety scale which was obtained 0.91 [27].

Beck Depression Inventory-II: It is one of the best tools for depression reflection. The questionnaire contains 21 items which measure physical, behavioral and cognitive depression. For each item, the degree of depression is determined with 4 options from mild to severe [28]. This questionnaire concerns the psychological characteristics of depression more than the physical and psychological problems. Its correlation with 
the Hamilton questionnaire is $75 \%$. The results of a meta-analysis on the Beck Depression Inventory showed that the internal consistency coefficient was $73 \%$ to $93 \%$ with the mean of $86 \%$. Besides, the alpha coefficient for the beck depression inventory was reported $86 \%$ for the patient group and $81 \%$ for control group. The validity and reliability for the second edition of the Beck depression on the students at Tehran University and Allameh Tabatabai was as follows: Cronbach's alpha was $78 \%$ and testretest reliability for two weeks was 73\% [24]. Meta cognitive beliefs questionnaire: This 30-item questionnaire was designed by Wells and Cartwright [29]. It measures a range of beliefs about worry, intrusive thoughts and cognitive processes based on Likert scale. The questionnaire consists of $5 \mathrm{sub}$ scales including cognitive confidence, positive beliefs about worry, cognitive awareness, negative beliefs about worry and the need to control dangerous thoughts. A study on the Iranian sample reported the validity and reliability of this tool as follows: Cronbach's alpha for the total scale was $91 \%$ and for the sub-scales of uncontrollability, positive beliefs, cognitive awareness, cognitive confidence and the need to control thoughts, it was orderly $81 \%, 86 \%, 87 \%, 80 \%$ and $71 \%$. Its validity was $87 \%$ respectively [30].

\section{Results}

Age range of participants (143 mothers of children with mental disorders) was between 19 and 42 years. The mean age of mothers was $29.36 \pm 5.41$. The including criteria was at least finishing the guidance education and most participants had Diploma or under Diploma education. The type and severity of the children disease was not concern to the experimenters so it was not controlled.

For the first objective of the study, the ANCOVA test was used to compare the amount of anxiety and depression. Levin test showed that the assumption of variance homogeneity for both variables was true. Table 1 represents the descriptive results and Table 2 shows ANCOVA test for both variables of anxiety and depression.

Table 1 The mean and standard deviation (SD) of anxiety and depression scores among mothers

\begin{tabular}{llclc}
\hline Group & \multicolumn{2}{c}{ Anxiety } & \multicolumn{2}{c}{ Depression } \\
\hline Mothers of children with mental disorders & Mean & SD & Mean & SD \\
& 41.04 & 6.48 & 48.85 & 6.29 \\
\hline
\end{tabular}

According to Table 1, the depression rate in the mothers of children with mental disorders was higher than their anxiety.

Table 2 shows that, the level of meta-cognition for low confidence cognition toward memory and attention, negative beliefs about thoughts, positive meta-cognition beliefs about worry and uncontrolled meta-cognition beliefs orderly received high scores while cognitive self-awareness received the lowest score.

Table 2 The mean and standard deviation of meta-cognition components

\begin{tabular}{lcc}
\hline Groups & Mothers of children with mental disorders \\
\hline & Mean & Standard Deviation \\
\hline Positive meta-cognition beliefs about worry & 14.98 & 6.62 \\
Uncontrollable meta-cognition beliefs & 13.94 & 6.76 \\
Low cognitive confidence toward memory and attention & 18.87 & 6.71 \\
Negative beliefs about thoughts & 15.67 & 7.97 \\
Cognitive self-awareness & 9.49 & 6.41 \\
\hline
\end{tabular}

Table 3 presents the Pearson correlation coefficient between variables. It shows that what relationship exists between anxiety and depression with meta-cognition. Table 4 showed that the difference between anxiety variable, depression and meta-cognition is significant. In addition, there was a significant positive relation between meta-cognition and depression. 
Meta-cognition, mental health in the mothers

Table 3 The results of multi-way analysis of variance for the study variables regarding the meta-cognition

\begin{tabular}{|c|c|c|c|c|c|c|c|}
\hline Groups & $\begin{array}{l}\text { Sum of } \\
\text { squares }\end{array}$ & $\begin{array}{c}\text { Degrees of } \\
\text { freedom }\end{array}$ & $\begin{array}{c}\text { Mean } \\
\text { square }\end{array}$ & $\mathrm{F}$ & P-value & Effects & $\begin{array}{c}\text { Statistical } \\
\text { power }\end{array}$ \\
\hline Positive meta-cognition beliefs about worry & 6.838 & 1 & 6.838 & 4.127 & 0.107 & 0.072 & 0.473 \\
\hline Uncontrollable meta-cognition beliefs & 6.832 & 1 & 6.832 & 4.113 & 0.195 & 0.05 & 0.416 \\
\hline $\begin{array}{l}\text { Low cognitive confidence toward memory } \\
\text { and attention }\end{array}$ & 5.278 & 1 & 5.278 & 3.310 & 0.167 & 0.04 & 0.271 \\
\hline Negative beliefs about thoughts & 7.125 & 1 & 7.125 & 4.864 & 0.083 & 0.312 & 0.593 \\
\hline Cognitive self-awareness & 5.672 & 1 & 5.672 & 3.143 & 0.189 & 0.118 & 0.391 \\
\hline
\end{tabular}

Table 4 Correlation matrix among mothers of children with mental disorders

\begin{tabular}{lcccccc}
\hline Variable & \multicolumn{2}{c}{ Anxiety } & \multicolumn{2}{c}{ Depression } & \multicolumn{2}{c}{ Meta-cognition } \\
\cline { 2 - 7 } & $\mathrm{r}$ & $\mathrm{p}$ & $\mathrm{r}$ & $\mathrm{p}$ & $\mathrm{r}$ & $\mathrm{p}$ \\
\cline { 2 - 7 } Anxiety & - & - & 0.73 & 0.001 & 0.57 & 0.001 \\
Depression & 0.73 & 0.001 & - & - & 0.16 & 0.001 \\
Meta-cognition & 0.57 & 0.001 & 0.16 & 0.001 & - & - \\
\hline
\end{tabular}

\section{Discussion}

This study aimed to compare the components of meta-cognition, anxiety and depression of mothers having children with mental disorders or disability. The results of the current study showed that the depression rate among the mothers of children with mental disorders was higher than their anxiety. The mothers of children with mental disorder have low mental health, inappropriate functioning, mood and emotional disorders. Literature review showed that although having a child gives a sense of joy, proud and personal development, it also brings about challenges [1]. When a child with special needs born in a family, not only special care is required but also his mother is affected due to her higher adjustment with child compared to others. In fact in our society, for some reasons like having more time, the mothers are more involved in their children issues compared to the fathers. Thus the mothers more interact with their children. The mothers of children with mental disorders are under a lot of stress and pressure, and consequently experience depression and anxiety because of their high stress [31]. In fact, depression often starts when major changes happen to the individual's life in which the individual has to withdraw important people or issues related to for example his home or work place. Also, prior studies have shown that there is a positive relationship between the incidence of negative stress and the onset of depression. About 20 to $50 \%$ of people with severe stress experience depression [3]. A child with mental disorders brings about mental and objective pressure on his family, especially his mother [7]. The parents of mental disorder children not only face with child care, but also they should care of patient's siblings who suffer from subliminal disorders to a greater extent than others [10]. When there is a child with a mental disorder in the family, his brothers and sisters probably are in trouble also [8]. Many parents of children with mental disorders cannot transfer the care of their children to others so they will not devote their time to themselves. It consequently interrupts their parental relationship and leads to marital satisfaction [3] which is the source of depression.

Studies reveal that a troubled child causes depression, physical and mental stress among his family especially his mother. The parents of children with mental disorders experience mental disorder, a sense of worthlessness and guilt, impaired physical functioning and fatigue [33]. According to prior studies, the mothers of children with severe disorders such as external disorders have also reported physical problems [34].

The mothers of children with mental disorders, after their child birth with special needs, feel guilty due to delivering a child with special 
need thus they fail to have the feeling of being mother. They dedicate themselves for their children and forget their own needs [6]. The mother usually chooses to be a house wife and mostly takes care of her child. Therefore, having children with special needs would be an important factor in losing social activity opportunities for their mothers which will increase depression prevalence among these mothers. The families of children with mental disorders less benefit from health, education and prevention services (depending on their society) which not only affects the disability incidence in these families but also increases the family problems [23].

The results of this study suggest that the depression rate of mothers is higher than their anxiety. These results are consistent with those of Habibi, Darvishi [23], Zamani, Habibi [3] and Hastings [35]. They reported that the mothers experience a sense of worthlessness, guilt, impaired physical functioning and fatigue. They argued that a reason of depression in these mothers is their negative feelings. They believed that sometimes these mothers depression is due to the outcomes associated with their children illness such as labeling. These outcomes are not limited to patient's close relatives; they are transmitted through generation and spread to larger sections of the family. This is a psychological trauma that is often ignored and would be an important reason of isolation which leads to depression in these families [3].

Another result of the study was about the level of meta-cognition among the mothers of children with mental disorders. Orderly, low confidence cognition toward memory and attention, negative beliefs about thoughts, positive metacognition beliefs about worry and uncontrolled meta-cognition beliefs received high scores while emotional awareness received the lowest score. As mentioned previously, the mothers of children with mental disorders had negative thoughts and beliefs. These thoughts spread to other aspects of their life which results in guilty feeling and uncontrollable behaviors that are due to their emotional instability and individual meta-cognition.
The innovation of this study was its conduction on a group of mothers with high emotional suffering and unpredictable results. The limitation of this study was lack of access to families with children suffering from different severity and types of disorders. In addition, the findings can be generalized to those mothers that come over caring their children. At the end, the study sample was only composed of women. Thus, the findings of this study are applicable only to the mothers of patients with mental disorders. More precisely, it is recommended that further studies evaluate the efficacy of this approach on the patients with different severity and types of diseases.

\section{Conclusion}

This study showed that the anxiety and depression were high in the mothers of children with special needs and their psychological health was low. We should focus on solving the problems of family members which arise from systemic attitude to solve these problems principally.

\section{Acknowledgments}

The authors would like to acknowledge all participants of the study as well as the cooperation of Moghtadaie, Salehi, Salamat, Mohammadian, Honjanibecause in conducting study on the mothers of children with attention-deficit hyperactivity disorder and their recommendation to perform the current study.

\section{Authors' contributions}

Study design: NZ

Data Collection and Analysis: NZ, MD

Manuscript preparation: NZ, MH, SS

All authors have read and approved the final version.

\section{Conflict of Interest}

"The author declares that they have no competing interests."

\section{Funding}

The author (s) received no financial support 
for the research, authorship and/or publication of this article.

\section{Availability of data and materials}

The datasets used and/or analyzed during this study are available from the corresponding author on reasonable request.

\section{References}

1- Ostberg M. Parental stress, psychosocial problems, and responsiveness in help-seeking parents with small (2-45 months old) children. Acta Peadiatrica1998; 87(1): 69-76.

2- Crinc KA, Greenberg MT. Minor parenting stresses with young children. Child Dev1990; 61(5): 1628-37.

3- Zamani N, Habibi M, Darvishi M. To compare the effectiveness of dialectical behavior therapy and cognitive behavioral group therapy in reducing depression in mothers of children with disabilities. Arak University of Medical Sciences Journal2015; 18(1): 32-42.

4- Dowdell EB. Caregiver burden: grandmothers raising their hight risk grandchildren. J psychology. J Psychosoc Nurs Ment Health Serv1995; 33(3): 27-30.

5- Hankin CS. ADT-ID and its impact on the family. Drug Benefits Trends2001; 13: 15-6.

6- Stansfield SA, Marmot MG. Social class and minor psychiatric disorder in British civil servants: a validated screening survey using the general health questionnaire. Psychol Med1992; 22(3): 739-49.

7- Sanders JL, Morgan SB. Family stress and adjustment as perceived by parents of children with autism or Down syndrome: implicatiations for intervention. Child Fam Behav Ther1997; 19(4): 15-32.

8- Sartorius N, Leff J, Lopez J, Ibor L, Maj M, Okasha A. Family \& Mental Disorders: from burden to empowerment. Chichester, UK; Wiley: 2008.

9- Kogel RL. Consistent stress pofile in mothersof children with autism. J Autism Dev Disord1992; 22(2): 205-16.

10- Barlow DH, Durand VM. Abnormal psychology: an integrative approach. Belmont, CA, US: Thomson brooks/ cole publishing Co; 1995.

11- Lainhart JE. Psychiatric problems in individuals with autism, their parents and siblings. Int Rev Psychiatry1999; 11(4): 278-98.

12- Hames A. Do the younger siblings of learning disabled children see them as similar or different? Child Care Health Dev1998; 24(2): 157-68.

13- Bhavnagar N. Low income African American mothers' parenting stress and instructional strategies to promote peer relationships in preschool children. Early Educ Dev1999; (10): 551-71.

14- Sadock BJ, Sadock VA, Ruiz P. Kaplan and sadock comperehensive text book of psychiatry. US, Philadelphia:
Lippincott Williams \& Wilkins; 2012.

15- World Health Organization. Mental health: facing the challenges, building solutions. WHO Pub; 2010.

16- Fisher PL, Wells A. Metacognitive therapy for obsessive-compulsive disorder: a case series. J Behav Ther Exp Psychiatry2008; 39(2): 117-32.

17- Zamani N, Zamani S, Habibi M. A comparison between the effectiveness of dialectical and cognitive behavioral therapy on the mental health of mother. $J$ Research \& Health2019; 9(1): 53- 61.

18- Moghtadaei K, Salehi M, Salamat M, Mohammadian Y, Honjani E. Relationship between meta-cognition with anxiety and depression in mothers of children with attention deficit and hyperactivity disorder (ADHD) compared with mothers of normal children. Journal Research in Behavioral Sciences2013; 11(1): 18-29.

19- Ellis A. Reason and emotion in psychotherapy. New York: Lyle Sturt; 1962.

20- Hawton K, Salkovkis PM, Kirk J, Clark DM. Cognitive behaviour therapy for psychiatric problems a practical guide. Oxford: press Oxford universi; 1989.

21- Bohus M, Haaf B, Stiglmayr C, Pohl U, Böhme R, Linehan M. Evaluation of inpatient dialectical-behavioral therapy for borderline personality disorder--a prospective study. Behav Res Ther2000; 38(9): 875-87.

22- Hawton K, Salkovskis PM, Kirk J ,Clarck DM. Cognitive behavior therapy for psychiatric problems: a practical guide. Translated by: Ghasemzadeh H. Tehran: Arjomand publication; 2002.

23- Zamani N, Habibi M, Darvishi M. Compare the effectiveness of dialectical behavior therapy and cognitive Behavioral Group Therapy in Reducing Depression in Mothers of Children with Disabilities. Arak Medical University Journal2015; 18(94): 32-42.

24- Fathiashtiani A, Dadsetan M. Psychological Tests personality and mental health. Tehran: Besat pub; 2009. 25- Spielberger CD. Manual for the state trait Anxiety Inventory: STAI (Form Y). Palo Alto, CA: Consulting psychologists press; 1983.

26- Spielberger CD, Gorsuch R, Lushene RE. Manual for the state trait Anxiety Inventory Palo Alto, CA: Consulting Psychologists Press; 1983.

27- Mahram B. Manual for the state trait Anxiety Inventory IN Mashhad city. [thesis]. General psychology. Tehran: Alame university; 2000.

28- Beck AT, Steer RA, Brown GK. Manual for the beck depression inventory-II. San Antonio, TX: The psychological corporation; 2000.

29- Wells A, Cartwright-Hatton S. A short form of the metacognitions questionnaire: properties of the MCQ30. Behav Res Ther2004; 42(4): 385-96.

30- Shirinzadeh Dastgiri S, Gudarzi MA, Ghanizadeh A, Taghavi SMR. Comparison of metacognitive and responsibility beliefs in patients with obsessive- 
compulsive disorder, generalized anxiety disorder and normal individuals. Iran Journal Psychiatry Clincal Psychology2008; 14(1): 46-55.

31- Jordan BK, Marmar CR, Fairbank JA, et al. Problems in families of male Vietnam veterans with posttraumatic stress disorder. J Consult Clin Psychol1992; 60(6): 916-26.

32- Schieve LA, Blumberg SJ, Susanna CR,. The relationship between autism and parenting stress. Pediatrics2007; 119 (1):114-21.

33- Hedov G, Anneren G, Wikblad K. Self- perceived health in Swedish parents of children with Down syndrome. Quality of Life Research2000; 9(4):415-422. 34- Freeman NL, Perry A, Factor DC. Child behaviors as stressors: replicating and extending the use of the CARSas a measure of stress: a research note. The Journal of Child Psychology and Psychiatry1991; 32(6): 1025-30.

35- Hastings RP. Child behaviors problems and parental mental health as correlates of stress in mothers and fathers of children with Autism. $J$ Intellect Disabil Res 2003; 47(4): 231-7.

Copyright $\odot 2016$ ASP Ins. This open-access article is published under the terms of the Creative Commons Attribution-NonCommercial 4.0 International License which permits Share (copy and redistribute the material in any medium or format) and Adapt (remix, transform, and build upon the material) under the Attribution-NonCommercial terms. 